\title{
INTEGRATION OF GEOMATICS TECHNIQUES FOR DIGITIZING HIGHLY RELEVANT GEOLOGICAL AND CULTURAL HERITAGE SITES: THE CASE OF SAN LEO (ITALY)
}

\author{
V. A. Girelli, L. Borgatti, M. Dellapasqua, E. Mandanici, M. C. Spreafico, M. A. Tini, G. Bitelli
}

DICAM, Dept. of Civil, Chemical, Environmental and Materials Engineering, Alma Mater Studiorum University of Bologna, Italy (valentina.girelli, lisa.borgatti, mirko.dellapasqua, emanuele.mandanici, margherita.spreafic2, mariaalessandra.tini,

gabriele.bitelli,)@unibo.it

KEY WORDS: Geomatics, CH documentation, Environmental Monitoring, San Leo

\begin{abstract}
:
The research activities described in this contribution were carried out at San Leo (Italy). The town is located on the top of a quadrangular rock slab affected by a complex system of fractures and has a wealth of cultural heritage, as evidenced by the UNESCO's nomination.

The management of this fragile set requires a comprehensive system of geometrical information to analyse and preserve all the geological and cultural features. In this perspective, the latest Geomatics techniques were used to perform some detailed surveys and to manage the great amount of acquired geometrical knowledge of both natural (the cliff) and historical heritage. All the data were also georeferenced in a unique reference system.

In particular, high accurate terrestrial laser scanner surveys were performed for the whole cliff, in order to obtain a dense point cloud useful for a large number of geological studies, among others the analyses of the last rockslide by comparing pre- and post-event data.

Moreover, the geometrical representation of the historical centre was performed using different approaches, in order to generate an accurate DTM and DSM of the site. For these purposes, a large scale numerical map was used, integrating the data with GNSS and laser surveys of the area.

Finally, many surveys were performed with different approaches on some of the most relevant monuments of the town. In fact, these surveys were performed by terrestrial laser scanner, light structured scanner and photogrammetry, the last mainly applied with the Structure from Motion approach.
\end{abstract}

\section{INTRODUCTION}

The preservation of historical and cultural heritage is a crucial issue in Italy, because, on the one hand, no other country in the world is so rich in cultural evidence but, on the other hand, it has a very fragile territory, often tormented by natural disasters such as earthquakes, landslides, floods.

In such a complex situation, a capillary and accurate documentation of each heritage site becomes even more necessary, being the fundamental base to plan all the operations of conservation and restoration.

In the architecture and construction sectors, the HBIM (Historical Building Information Model) is nowadays increasingly used (Oreni et al., 2014; Bitelli et al., 2017); when the object size increases and the surrounding environment becomes an essential part in the study and monitoring process, a 3D GIS (Geographic Information System) can be the shared knowledge base capable of providing an accurate geometric description of the case study, available for all the technical figures involved (Dore \& Murphy, 2012, Ruoss et al., 2013).

The first phase of the documentation process is obviously the survey, often performed by a multi-scale and multi-technique approach, involving the integration of different geomatic techniques (Bitelli et al., 2011; Campana et al., 2012).

In particular, Terrestrial Laser Scanner (TLS) and digital photogrammetry with the multi-view Structure from Motion (SfM) approach constitute often the favoured methods for the description and documentation of cultural heritage, thanks to their capability to generate very dense and accurate point clouds also enriched by the radiometric RGB information (Remondino, 2011). With the support of Global Navigation Satellite Systems
(GNSS), it is also possible to frame all the collected data in a unique and well established reference system.

In this work, the application and integration of these geomatic techniques to the case study of San Leo (Italy) is presented (Figure 1).

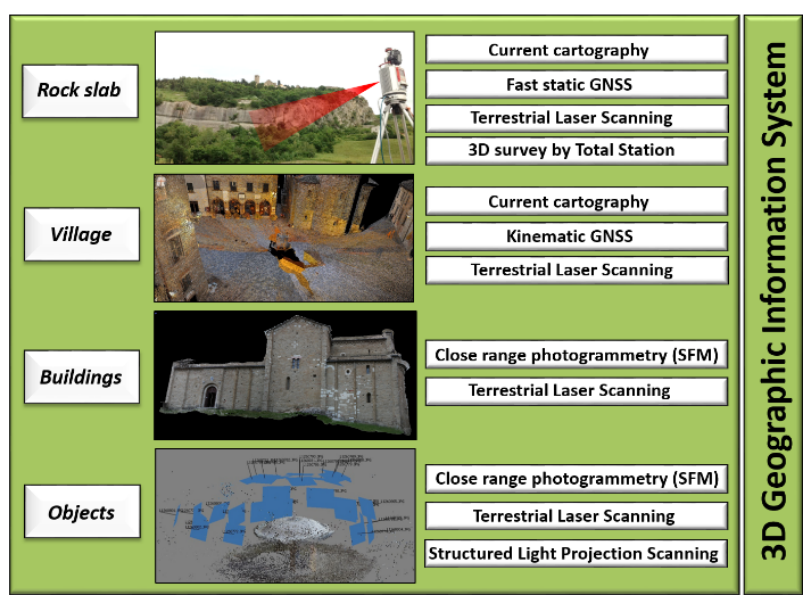

Figure 1. Scheme of the geomatic techniques applied at different scales of investigation in San Leo site.

The small village is in fact a good example of a rich exhibition of cultural and historical heritage, associated to a high geological risk, because of the instability phenomena associated to its particular geological and geomorphological setting (Spreafico et al., 2014). 
These aspects required a complex whole of surveying activities, started in 2013. The final aim is to realize a massive 3D database able to maintain and connect all the relevant information, at the most suitable scales, to support different activities concerning geological analysis for landslide risk assessment and Cultural Heritage conservation and valorisation. After the presentation and description of the case study, all the surveying activities will be described, with particular attention to the technological solutions adopted in the various phases.

The scientific work is complemented by the didactic activity, through which the Engineering students can try and experiment on the field different operating methods at different scales of analysis, in a significant and stimulating multidisciplinary context.

\section{THE CASE STUDY}

The small medieval village of San Leo is located near Rimini, in the middle valley of the Marecchia River, in the north-east of the peninsula.

The town of San Leo was once called Monte Feltro, from Mons Feretrus, a name linked to the important Roman settlement built around a temple dedicated to Jupiter Feretrius and dates back to the III century BC.

The early Christian period (2nd century AD) was characterized by its evangelization following the arrival of Leo and Marino, two Dalmatian stonecutters who founded the Christian communities of San Leo and San Marino thus favouring the spread of Christianity throughout the area until the foundation of the diocese of Montefeltro. In particular, San Leo was the first bishop of the district and gave the village his current name. San Leo is rich of relevant historical monuments and has an important cultural heritage. The oldest building is the parish church, the Pieve, which collects around itself the nucleus of the medieval village; after the VII Century, the Cathedral was erected beside, consecrated to the cult of San Leo. In 1173 it was completely renewed, in the Romanesque-Lombardy style, and united to the mighty bell tower, of probable Byzantine origin.

Separated from the town, for obvious defensive reasons, is the medieval castle, built on top of a rock spur.

The fortress was the protagonist of important military events during the Renaissance period, which fuelled the fame of its inexpugnability.

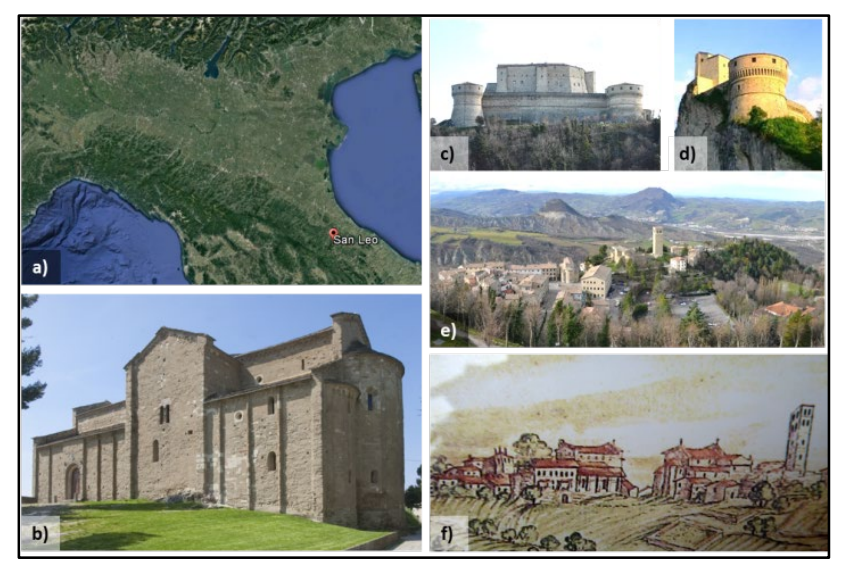

Figure 2. a) San Leo location; b) the Cathedral; c) and d) the medieval fortress; e) the village seen from the castle; f) the Pieve, the Cathedral and the bell tower in a watercolour painting by Francesco Mingucci, 1626.
Under the Papal State, the castle lost its military purpose and was adapted to prison. At the end of 1700 , the Count of Cagliostro, one of the most enigmatic adventurers and occultists of the Age of Enlightenment, was here imprisoned.

San Leo never needed walls. In fact, the village rises on a rock slab, characterized by a size of $500 \times 600 \mathrm{~m}$, with impregnable vertical faces up to $100 \mathrm{~m}$ high (Figure 3).

Against the impressive calcarenite and sandstone quadrangular plateau is affected by lateral spreading associated with secondary rock falls and topples. A number of landslides endangered the historical town since centuries (Benedetti et al., 2011), the last one in February 2014 (Borgatti et al., 2014; Spreafico et al., 2015).

The small town thus constitutes a relevant example of natural and historical heritage, that needs to be studied, documented and preserved, given the high geological risk.

This aim requires a rich and detailed system of geometrical documentation, where the latest Geomatics techniques are used in an integrated way, as illustrated in the following paragraphs.

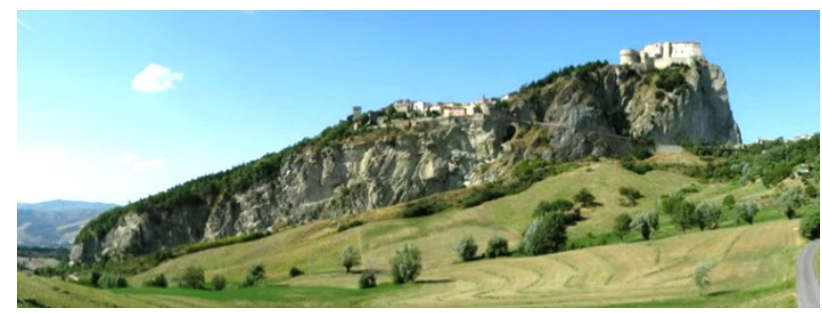

Figure 3. The village of San Leo on the top of the impregnable rock slab (view from the South).

\section{TLS AND GNSS IN SUPPORT OF THE GEOLOGICAL ANALYSIS}

The first surveys carried out by DICAM Dept. of Bologna University on the San Leo rocky slab took place in 2013, in order to realize a complete 3D model of the cliff to support geological analyses; further activities of surveying and data processing are still ongoing (Spreafico et al., 2014; Spreafico et al., 2015a).

The availability of a complete three-dimensional model, detailed and georeferenced, allowed to carry out analyses in order to extract the geometrical characteristics of the fractures (dip, dip direction and strike), even in areas that could be difficult to reach with traditional methods of geological survey. As a supplement to traditional surveys, the integration of different approaches permitted a remote and safe investigation of the geology and geomorphology, without any accuracy loss, in operational contexts that are actual issues for safety and accessibility.

As they were already available, a series of TLS scans, covering the northern and the east cliffs and acquired between 2008 and 2011, were exploited. The survey activity had to integrate the missing sides in order to complete the whole 3D model of the slab. For the survey of the south and west sides, 16 scanpositions were necessary, because of the many hidden surfaces of the investigated crag (Figure 4). The scans were acquired using a Riegl VZ400 laser scanner, characterized by $5 \mathrm{~mm}$ precision and a range of $400 \mathrm{~m}$. Scans were performed by taking a $2 \mathrm{~cm}$ scanning step at the farthest distance of each scene.

The reciprocal alignment of the clouds was performed through natural points or tie points materialized ad hoc with retroreflective targets. In addition, the model was georeferenced 
in the UTM-WGS84 cartographic system, thanks to a rapidstatic GNSS survey.
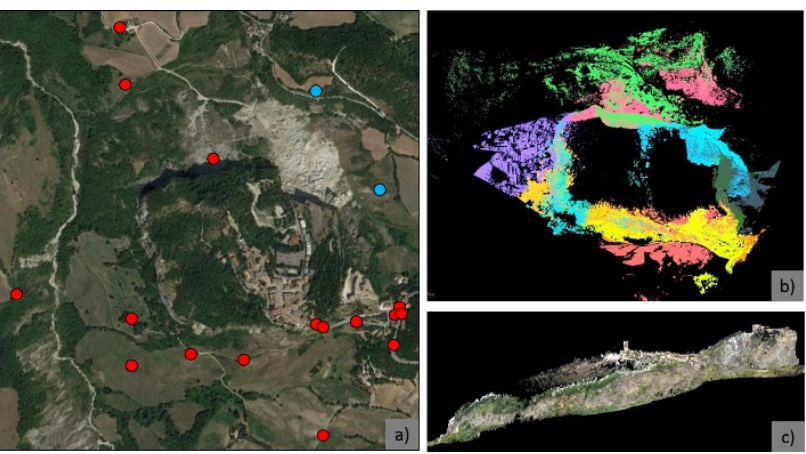

Figure 4. TLS surveys: a) scan-positions of the 2013 (red dots) and of 2014 (blue dots); b) aligned point clouds after 2013 surveys activities (about 900.000 .000 points); c) south side true coloured point cloud.

A second TLS survey was performed after the rockslide occurred on 27 February 2014, widely described in Borgatti et al. (2014). Two point clouds covering the slide area were acquired and georeferenced by the GNSS positioning of 3D spherical targets.

The comparison between the models before and after the rockfall (Figure 5) allowed to elaborate the pre-after geometries of the slope and, thanks to the 3D datasets, to extract the discontinuities characteristics and the block dimensions. Data extracted from the TLS point clouds and from traditional geomechanical surveys were employed for the development of a 3D numerical model for the stability simulation by means of Distinct Element methods (Spreafico et al., 2015b).

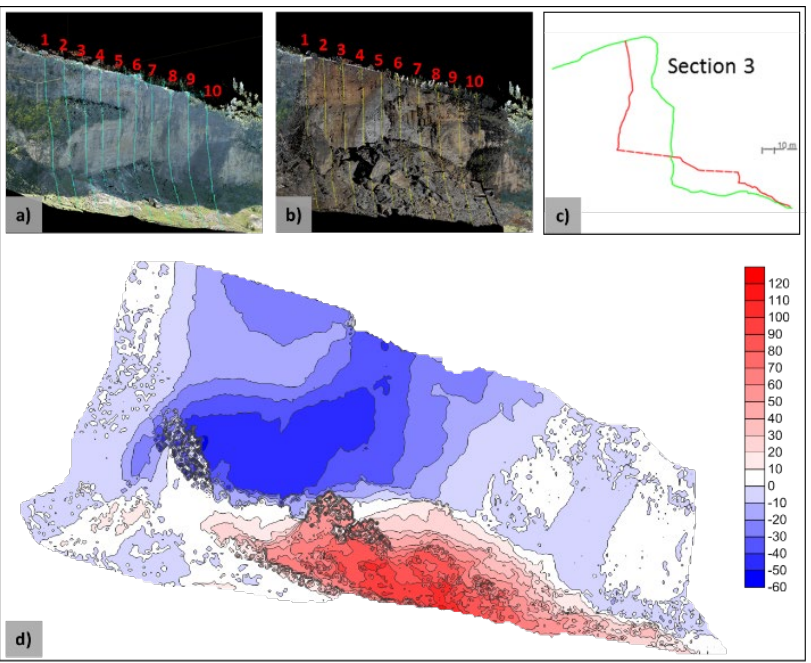

Figure 5. Comparison between point clouds before and after the 2014 slide: a) vertical sections on the point cloud before the failure; b) vertical sections on the point cloud after the failure; c) example of profiles obtained from the cloud sections; d) The comparison of the rock-face pre and post event (meters).

\section{THE SURVEY OF THE ROCK SLAB TOP AND OF THE URBAN CENTRE}

As explained in the previous paragraph, TLS and GNSS surveys were used to describe and give a 3D representation of the rock slab; however, the 3D clouds represent only the lateral vertical cliffs of the plateau, the most important for geological studies. On the top, the TLS survey was partially prevented by logistic constraints. The model of the slab was then completed integrating TLS clouds derived by surveys performed in the urban centre with data obtained by the digitalization of an existing large scale vector map and by kinematic GNSS surveys.

In particular, for the characterization of the urban centre, data derived by three different methodologies were used:

- Contour lines (equidistance $2 \mathrm{~m}$ ) and about 500 spot elevation points, derived by a digital vector map (scale 1:2000). Different strategies implemented in a GIS environment were tested and GRID and TIN DTM formats were obtained using the two kinds of available data, also with the aim to study the best methodological approach in this case study.

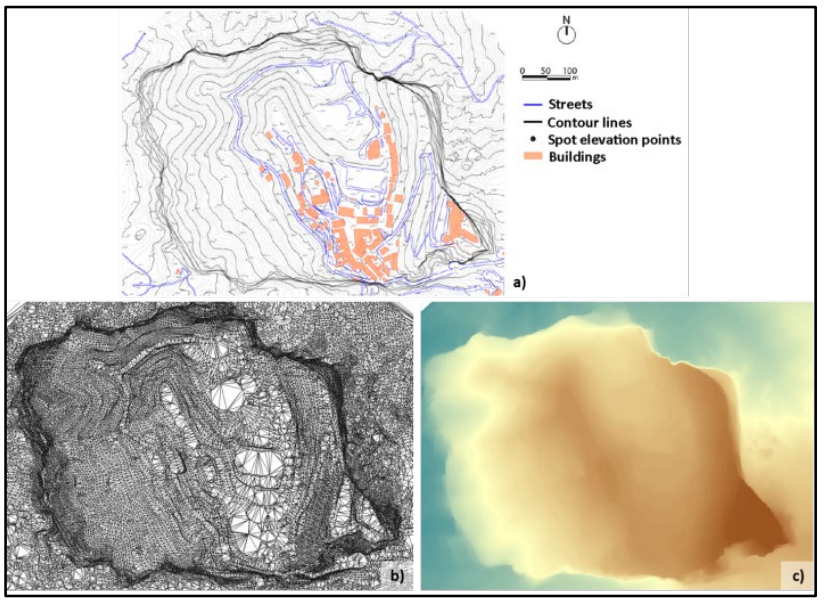

Figure 6. a) Vector map with the legend; b) the derived DTM in TIN format and then c) converted in raster format.

- GNSS surveys in kinematic and "stop \& go" procedures. For these surveys, a dual frequency Promark 500 receiver was used as master station on a pre-signalized point (located on the castle south fortified tower), whose position in UTM-WGS84 was computed by connecting it to four IGS Permanent Stations. As rover station, a Promark 3 receiver was used, performing a kinematic survey along the village streets and acquiring by stop and go method natural and well identifiable points, such as manhole cover and sidewalk corners.

- TLS surveys from a large number of scan positions located in four different areas of the village: the north and south castle fortified towers, the civic tower, the Cathedral and the main square of the village (Figure 8). The utilized system is the Riegl VZ400 coupled with the Nikon D90 camera for the RGB acquisition. Some point clouds were acquired tilting the instrument by a special cradle and using a forklift truck, in order to acquire also the buildings roofs. The clouds were aligned and inserted in UTM-WGS84 reference system using the natural points surveyed by GNSS as previously described and the ICP automatic algorithm; about 170 million points with a average spacing of $5 \mathrm{~cm}$ were acquired in total (Figure 9). 


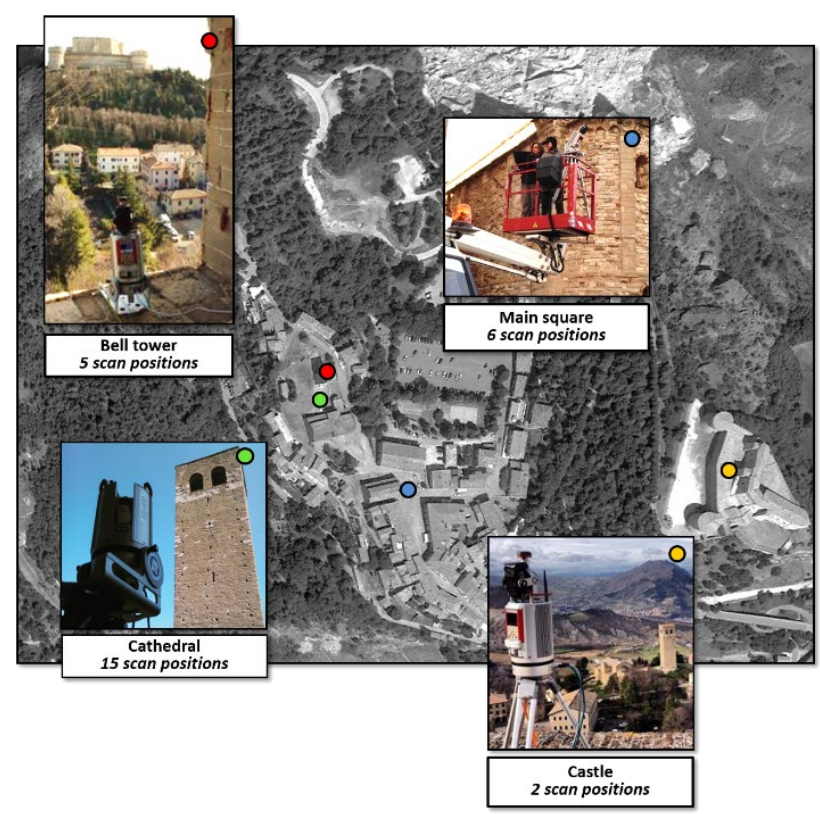

Figure 8. The area surveyed by the TLS, with in evidence the four points of acquisition.
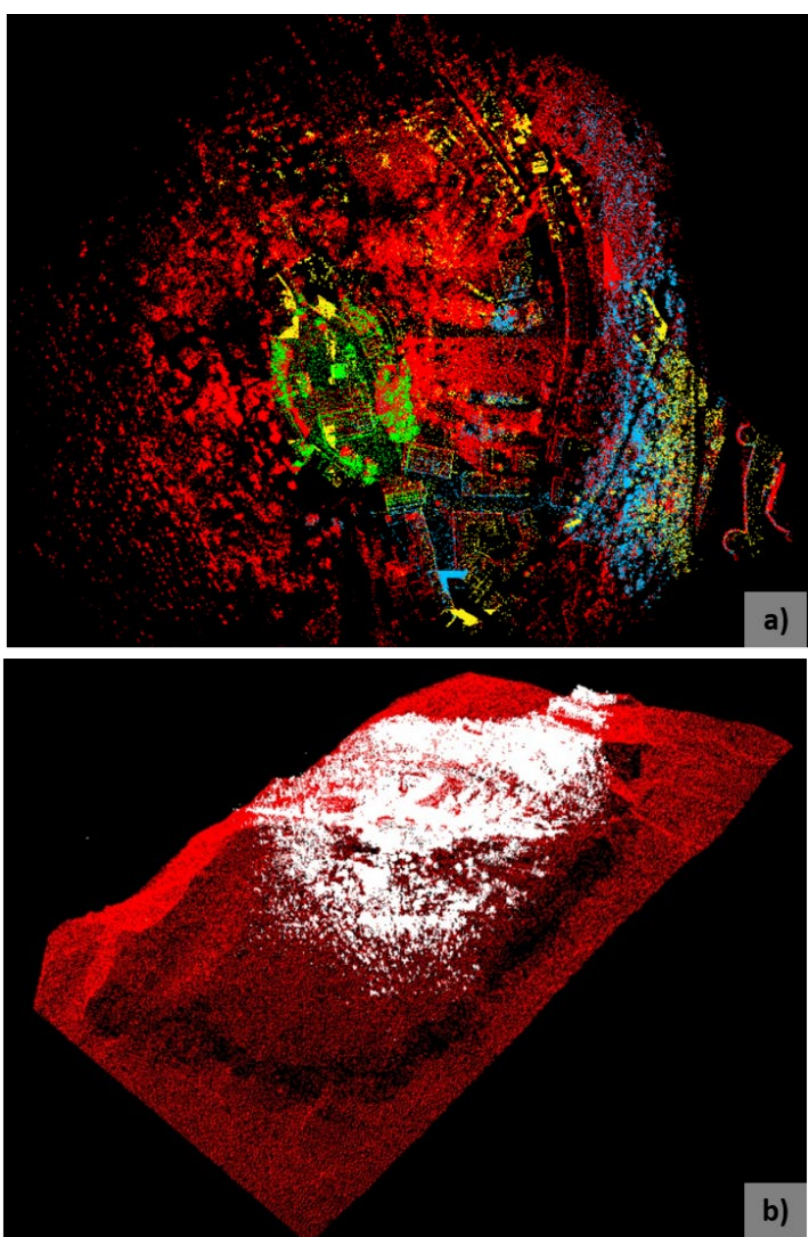

Figure 9. TLS surveys of the urban centre: a) the acquired point clouds; b) the point cloud of the whole slab (in red) and the clouds acquired by TLS on the top (white).

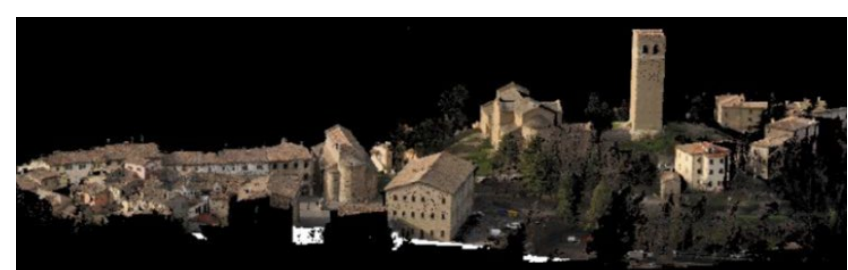

Figure 10. True coloured point cloud of the urban centre.

\section{TLS, SfM AND 3D SCANNING FOR OBJECTS MODELLING}

As already pointed out, San Leo is rich of monuments and art works of valuable historical interest. From 2013 to 2017, some of these items were surveyed, in order to obtain an accurate 3D metric documentation of them, with the aim to support their study, restoration if necessary, and preservation.

In particular, some monuments interested by the surveying activities are the Cathedral, the tower bell, the archaeological area discovered near the Cathedral and the fountain in the main square of the village.

The instruments used are various: TLS, digital photogrammetry with SfM approach, structured-light projection 3D scanning; the chosen methodological approach aims not only at a close integration of different techniques, but also at a critical comparison, in order to evidence problems and potentialities of each one.

Detailed surveys of the exterior and interior of the Cathedral and of the tower bell were carried out by means of TLS; moreover, for the exterior also SfM solution using a GoPro Hero4 on an extensible pole was tested, confirming the need of a previous careful camera calibration when using action cameras for photogrammetric purposes (Balletti et al., 2014).
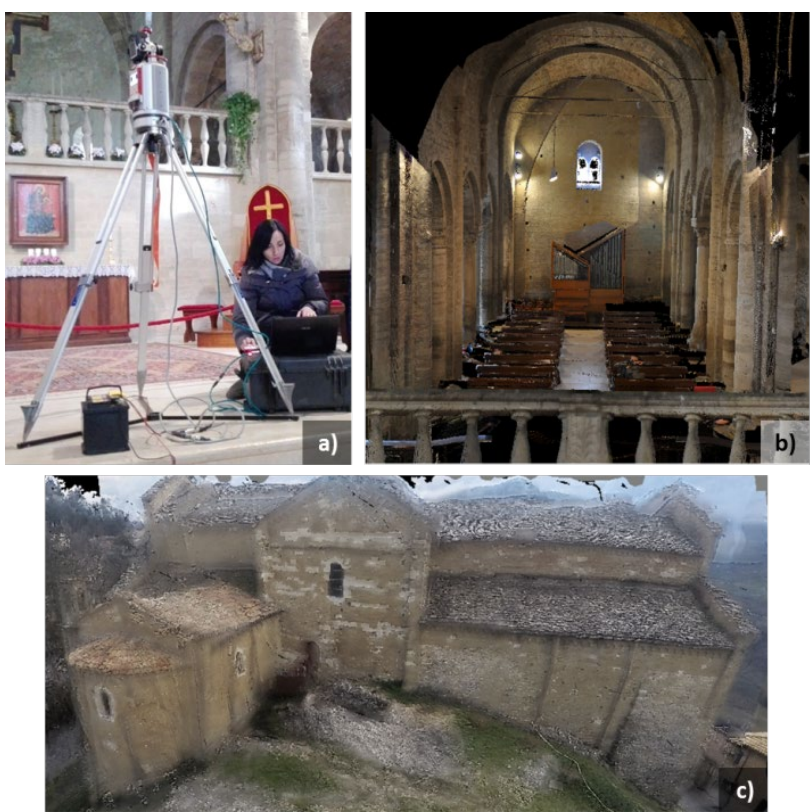

Figure 11. a) Surveying activities for the 3D documentation of the Cathedral: a moment of the TLS survey; b) a coloured point cloud of the interior; c) the textured mesh of the north façade by

SfM using a GoPro Hero4 action camera for the images acquisition. 
On the rock on which the Cathedral stands, near the civic tower, a prehistorical archaeological area was recently discovered, characterized by a lithic bath $(3.50 \times 3.00 \mathrm{~m})$ and numerous signs, symbols and figures carved on the rocks, probably using stone tools in prehistoric times and metal tools later.

These objects, not easy to date and not always clear in their purposes, were used in rituals with rainwater or another liquid and probably are related to the symbolic value of purification and fertility of water. The area is now a public archaeological park, whose layout has been made possible thanks also to the 3D model of the area, considering the complex topography of the site.

The lithic bath was surveyed using TLS and SfM; for the engravings, the structured-light projection 3D scanner Artec MHT (accuracy $0.1 \mathrm{~mm}$ ) was used.

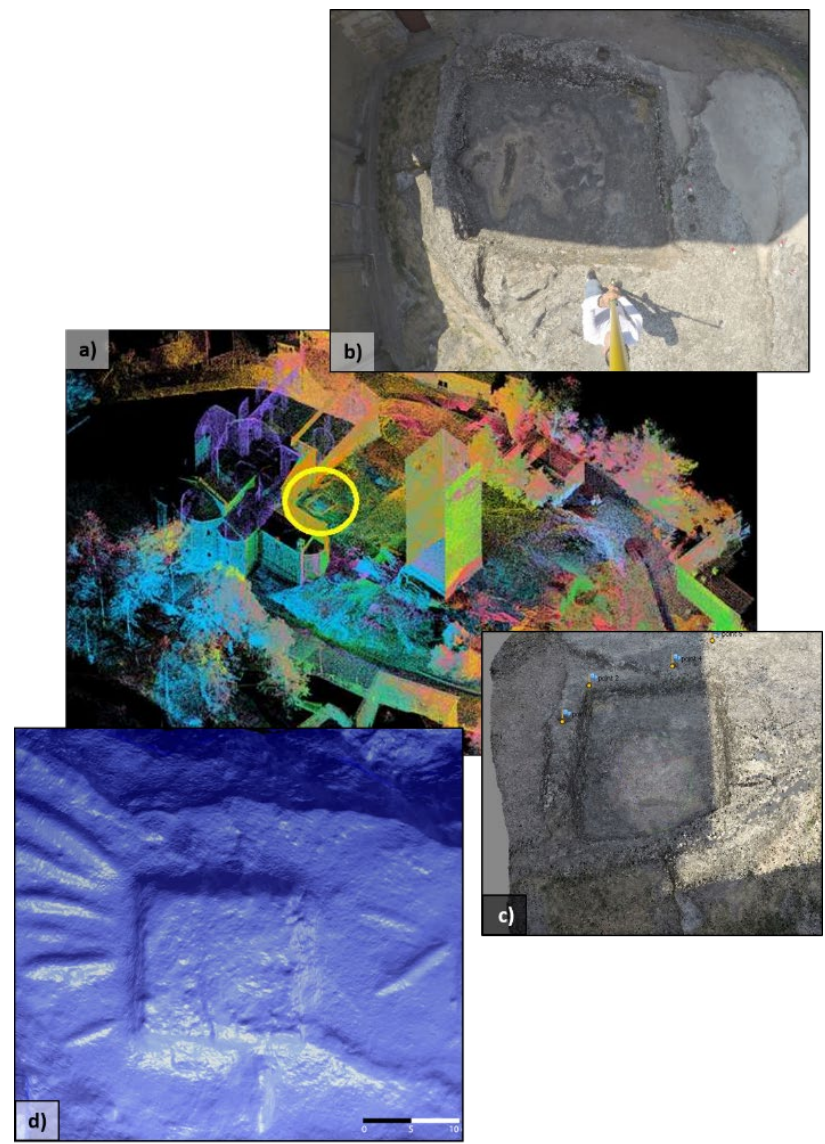

Figure 12. a) The location of the lithic bath near the Cathedral; SfM for the 3D reconstruction of the bath: b) an image acquired by GoPro Hero4 camera and c) the RGB point cloud; d) a particular of the mesh of an engraving obtained by structuredlight projection 3D scanning.

The fountain located in the village main square was surveyed using SfM, with the support of TLS to rigorously scale and georeference the 3D model. In particular, in this case a virtual restoration was performed: in fact, in November 2013 a strong storm cut down the elm of San Francesco, seriously damaging the monument.

The upper part of the fountain, today conserved in the Sacred Art Museum, has been reconstructed and then repositioned in its original position, virtually bringing back the fountain to its original aspect, as it appears in some historical illustrations and postcards of the square (Figure 13).
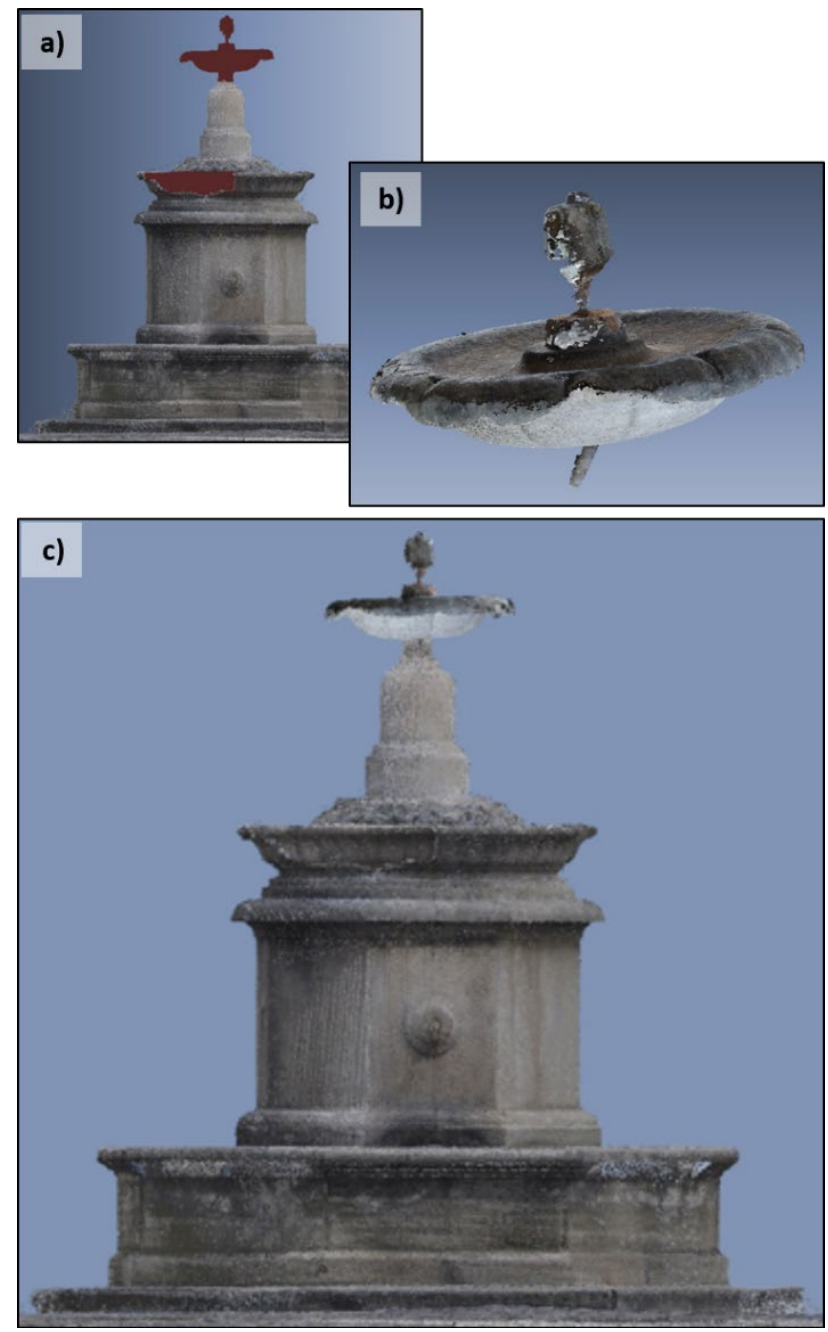

Figure 13. The 3D model of the fountain (about 250000 triangles) before (a) and after (c) the virtual restoration. In b) the damaged missing part reconstructed by SfM.

\section{CONCLUSIONS}

The surveying experiences conducted on the case study of San Leo in Italy has allowed to analyse potentialities and issues related to the integrated use of different geomatic techniques for the generation of accurate 3D models of the rock slab on which the village stands, of the urban centre and of some monuments of relevant historical and cultural interest.

In particular, regarding the rock slab, the obtained 3D model has proved to be suitable for the geological analysis, permitting accurate investigations in complete safety also in such a hazardous context; the study about the landslide of 2014 has demonstrated that the acquired data can also be used for any subsequent multi-disciplinary and/or multi-temporal study.

Regarding the Cultural Heritage of the site, the methodological choice made for the surveys and the data processing, which consists in the synergic use of different geomatic techniques, has allowed to obtain products characterized by high accuracy and rich descriptive capacity, both due to the point density and the availability of radiometric information. 
The geomatics activities in San Leo will continue in the future. A final purpose is, in fact, to store all the data in a multi-scale and multi-resolution GIS platform, able to support all the subjects interesting the different disciplines. Furthermore, being based on 3D data collected at different epochs (e.g. before and after the landslide), it will also permit some kinds of 4D analyses. Besides all this, the experimentation of an open lab for didactic experiences will continue.

\section{ACKNOWLEDGEMENTS}

Authors would like to thank Mauro Guerra, the mayor of San Leo, and the students Alessandro Pacini, Sara Gardini and Flavio Albertini.

\section{REFERENCES}

Balletti, C., Guerra, F., Tsioukas, V., Vernier, P., 2014. Calibration of Action Cameras for Photogrammetric Purposes. Sensors (Basel) 2014 Sep; 14(9): 17471-17490.

Benedetti, G., Bernardi, M., Borgatti, L., Continelli, F., Ghirotti, M., Cristiano, G., Landuzzi, A., Lucente, C.C., Marchi, G., 2011. San Leo: centuries of coexistence with landslides. The Second World Proceedings of the Second World Landslide Forum - 3-7 October 2011, Rome.

Bitelli, G., Gatta, G., Girelli, V.A., Vittuari, L., Zanutta, A., 2011. Integrated Methodologies for the 3D Survey and the Structural Monitoring of Industrial Archaeology: The Case of the Casalecchio di Reno Sluice, Italy. INTERNATIONAL JOURNAL OF GEOPHYSICS, pp. $1-8$.

Bitelli, G., Dellapasqua, M., Girelli, V.A., Sanchini E., Tini, M.A., 2017. 3D Geomatic techniques for an integrated approach to Cultural Heritage knowledge: the case of San Michele in Acerboli's Church in Sant'Arcangelo di Romagna. Int. Arch. Photogramm. Remote Sens. Spatial Inf. Sci., XLII-5-W1, 291296.

Borgatti, L., Guerra, C., Nesci, O., Romeo, R.W., Veneri, F., Benedetti, G., Landuzzi, A., Marchi, G., Lucente, C.C., 2015. The 27th February 2014 San Leo rock fall (northern Italy). Landslides 12(2), pp. 387-394.

Campana, S., Bianchi, G., Fichera, G.A., Lai, L., Sordini, M., 2012. 3D recording and total archaeology: From landscapes to historical buildings. International Journal of Heritage in the Digital Era, 1, 3, pp. 444-460.
Dore, C., Murphy, M., 2012. Integration of Historic Building Information Modeling and 3D GIS for Recording and Managing Cultural Heritage Sites. In VSMM2012. Proceedings of the 18thInternational Conference on Virtual Systems and Multimedia. Virtual Systems in the Information Society, pp. 369-376.

Oreni, D., Brumana, R., Della Torre, S., Banfi, F., Barazzetti, L., Previtali, M., 2014. Survey turned into HBIM: the restoration and the work involved concerning the Basilica di Collemaggio after the earthquake (L'Aquila). ISPRS Annals of the Photogrammetry, Remote Sensing and Spatial Information Sciences, Volume II-5, pp. 267-273.

Remondino, F., 2011. Heritage Recording and 3D Modeling with Photogrammetry and 3D Scanning. Remote Sensing, Vol. 3(6), pp.1104-1138.

Ruoss, E., Alfare, L., Vallone, R., Moscatelli, M., Zumaglini, M., Grunner, R., Klementschitz, R., Richard, L., 2013. GIS as Tool for Cultural Heritage Management. In book: Sustainable tourism as driving force for Cultural Heritage sites development, Planning, Managing and Monitoring Cultural Heritage Sites in South East Europe, Chapter: 3.5, Publisher: CNR IGAG, pp.42-46.

Spreafico, M.C., Franci, F., Bitelli, G., Girelli V.A., Landuzzi A., Lucente C.C., Mandanici E., Tini M.A., Borgatti L. 2014. Remote Sensing Techniques in a Multidisciplinary Approach for the Preservation of Cultural Heritage Sites from Natural Hazard: The Case of Valmarecchia Rock Slabs (RN, Italy). In: Engineering Geology for Society and Territory - Volume 8, Gewerbestrasse 11, Cham, CH-6330, Switzerland, SPRINGER INT PUBLISHING AG, pp. 317 - 321.

Spreafico, M.C., Perotti, L., Cervi, F., Bacenetti, M., Bitelli, G., Girelli, V.A., Mandanici, E., Tini, M.A., Borgatti, L., 2015a. Terrestrial Remote Sensing techniques to complement conventional geomechanical surveys for the assessment of landslide hazard: The San Leo case study (Italy). European Journal of Remote Sensing, 48, pp. 639 - 660.

Spreafico, M.C., Francioni, M., Cervi, F., Stead, D., Bitelli, G., Ghirotti, M., Girelli, V.A., Lucente, C.C., Tini, M.A., Borgatti L., 2015b. Back Analysis of the 2014 San Leo Landslide Using Combined Terrestrial Laser Scanning and 3D Distinct Element Modelling. Rock mechanics and Rock Engineering, 49, pp. 2235-2251. 